\title{
The fire assay reloaded
}

\author{
Paolo Battaini • Edoardo Bemporad • Daniele De Felicis
}

Published online: 5 September 2013

(C) The Author(s) 2013. This article is published with open access at SpringerLink.com

\begin{abstract}
The fire assay process is still the most accurate and precise method for measuring the gold content in gold alloys. Scanning electron microscopy and transmission electron microscopy have been applied to observe the change in microstructure of the samples undergoing the fire assay process. The performed observations reveal that the microstructure of the specimen is more complex than expected. Before the parting stage, the specimen is not a perfect gold-silver binary alloy but contains also copper-silver oxides and other residual compounds. The parting stage appears to be a dealloying process leading to a nanoporous gold nanostructure. What observed after partition explains the evolution of the shape and colour of the specimen and may allow for a better comprehension of the procedure and an improvement in the method.
\end{abstract}

Keywords Fire assay · Nanoporous gold · Dealloying · Parting stage $\cdot$ Inquartation

\section{Introduction}

The fire assay process has been well known since ancient times as a method for measuring the gold content of precious alloys. In fact, it was first mentioned by the Egyptians on a cuneiform tablet that dates back to about 1360 B.C. One of the first written proofs of the fire assay process lies in the De la Pirotechnia, by the Italian Vannoccio Biringuccio [1], born in Siena in 1480. Even now, it is still the most accurate and precise method, besides being the most popular in the goldsmith's field. This notwithstanding, very little information is available about the

P. Battaini $(\triangle)$

8853 Spa, Pero, Milan, Italy

e-mail: battaini@esemir.it

E. Bemporad · D. De Felicis

Mechanical and Industrial Engineering Department,

University of Rome "Roma Tre", Rome, Italy microstructural evolution of the specimen undergoing the different steps of the process. The present work is aimed at describing this evolution by means of scanning electron microscopy, transmission electron microscopy, as well as other analytical techniques. The performed observations reveal some unexpected microstructural changes, which cast new light on the whole process and allow for understanding the remarkable effectiveness of the method. Knowing why each step of a procedure is performed in turn helps the operator to avoid making mistakes.

\section{Materials and methods}

Different methods have been applied to study the microstructural evolution of materials undergoing the fire assay process. The surface of the specimen has been investigated by scanning electron microscopy (SEM) equipped with electron microanalysis (energy dispersive spectrometry, EDS), to determine its chemical composition. The same techniques have been applied to study the related metallographic sections. The nanostructures detected during the analyses and the microstructural features have been explored by focused ion beam (FIB) coupled with electron beam for imaging, ion milling and deposition [2]. Some analyses on thin foils extracted by FIB have been performed by transmission electron microscopy (TEM). The crystal structure of the thin foils has been studied by selected area electron diffraction inside the TEM. A calorimeter has been adopted to study the transition which occurs during the last annealing stage of the sample.

\section{Stages of the procedure, results and discussion}

The results of the microstructural analysis of the samples at each stage of the fire assay process will be given. The fire assay method is described in the International Standard ISO 11426:1997. The present work is not aimed at giving the details of the process and the operating procedure which are well known [3]. 


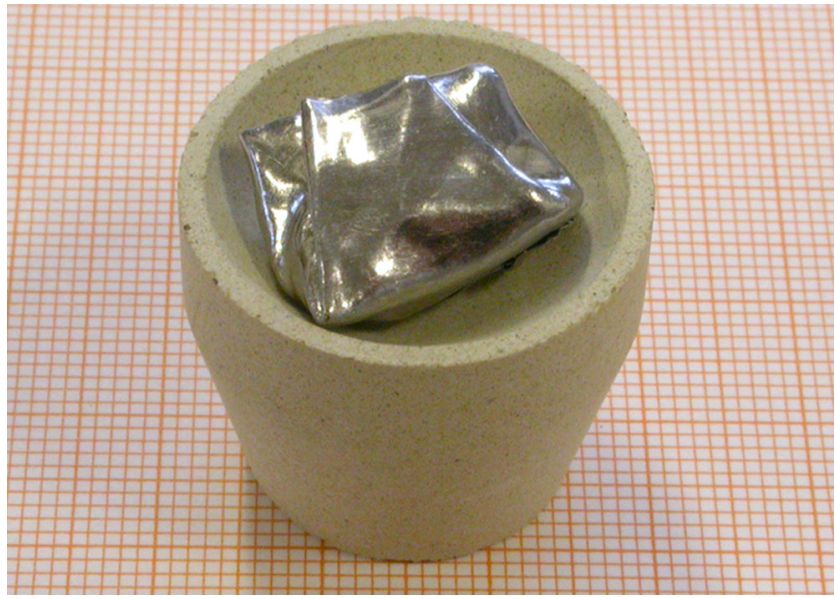

Fig. 1 Lead pouch containing the specimen and Ag, closed and placed on a cupel made of magnesium oxide, ready to undergo the in-furnace cupellation process

\section{Sampling and cupellation stages}

The first stage of the fire assay process is sampling. Sampling is a crucial stage, which is carried out according to the kind of product to control — ingot, jewel, coin, etc. It will generally be a chip or a small fragment of a material. The sample will have to weigh about $250 \mathrm{mg}$ to the maximum and to be weighed by means of precision balance sensitive to the hundredth of milligram.

Silver and lead are added to the specimen as described in the following. A sheet of pure lead of about $3 \mathrm{~g}$ is prepared for the assay of alloys whose titer is approximately 18 carats. The analyst makes an assumption about the kind of alloy the specimen has been taken from, then adjusts the weight of the lead sheet by increasing it by about $4 \mathrm{~g}$, when dealing with white or red gold. The weight of the lead sheet may also be about $7 \mathrm{~g}$ for a 14-carat alloy. An amount of pure silver-at least $999.5 \%$ pure $\mathrm{Ag}$, is prepared as well, according to the

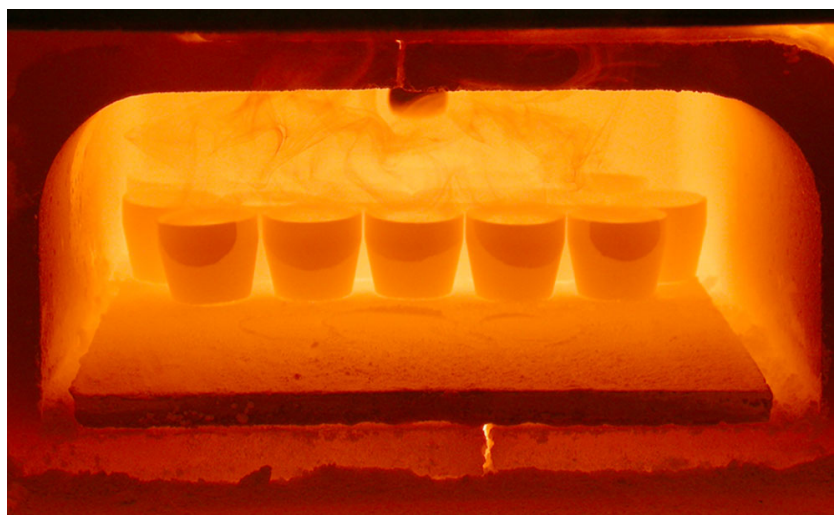

Fig. 2 Cupels containing the specimens in the furnace chamber at $1,150{ }^{\circ} \mathrm{C}$. The fumes are due to litharge (lead oxides, which takes place because of the presence of air). On the front of the cupels, a dark stain is visible, caused by lead oxides and other non-noble metals (base metals) oxides, which are about to be absorbed by the cupel

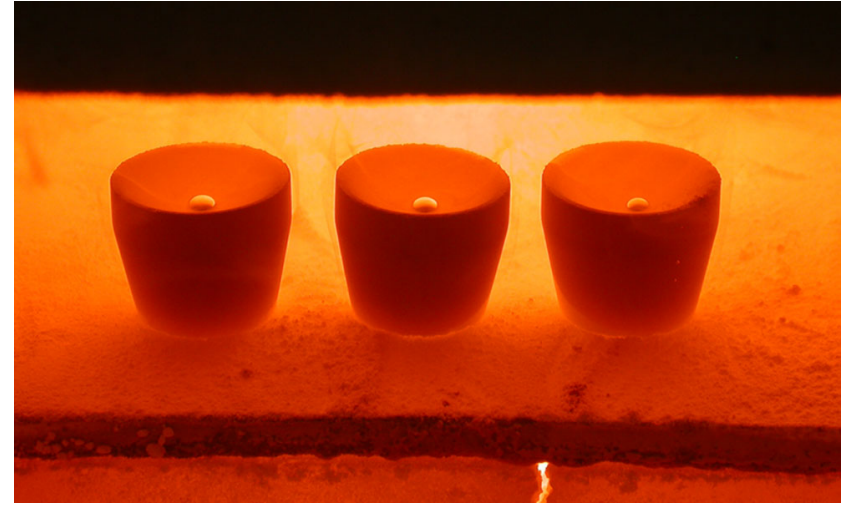

Fig. 3 At the end of the cupellation process, the beads remain on the cupels, gleaming and still

presumed gold content of the sample. This process is also known as inquartation and is aimed to dilute the gold in the sample. The small lead sheet, pouch-like folded is used to wrap up the sample and the silver. The pouch is then placed on a previously heated porous cupel (Fig. 1) made of magnesium oxides, already placed into the furnace at $1,150{ }^{\circ} \mathrm{C}$.

After that, the door of the furnace is kept closed for a short period of time in order to allow the temperature to increase to $1,150{ }^{\circ} \mathrm{C}$, then is left slightly opened to allow the oxygen of the air to enter. The cupellation process starts when the first oily droplets of litharge appear, floating on the cupel which absorbs them later. A small amount of litharge volatilizes releasing fumes (Fig. 2).

By the end of the process, an iridescent-banded film produced by extremely thin films of fluid litharge is observed on the surface of the residual bead. In the end, this thin film also
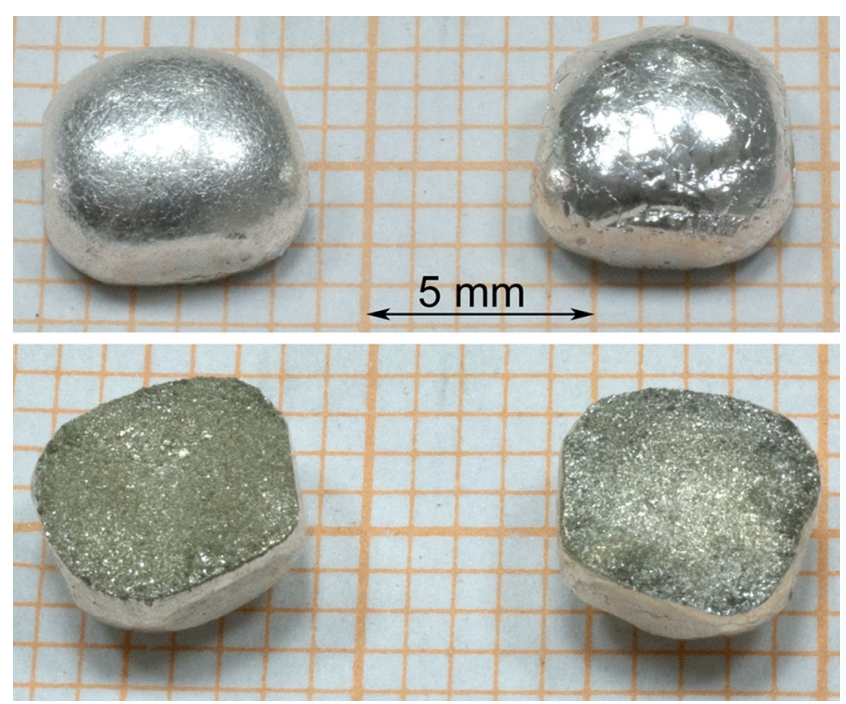

Fig. 4 At the end of the cupellation process, the upper surface of the beads is bright and smooth. Very often, as shown in the figure, very different solidification structures are observed (fine grain, on the left bead, coarse grain on the right bead). The lower part of the figure shows the surfaces of the two beads previously in physical contact with the cupels. They are rough and matt 

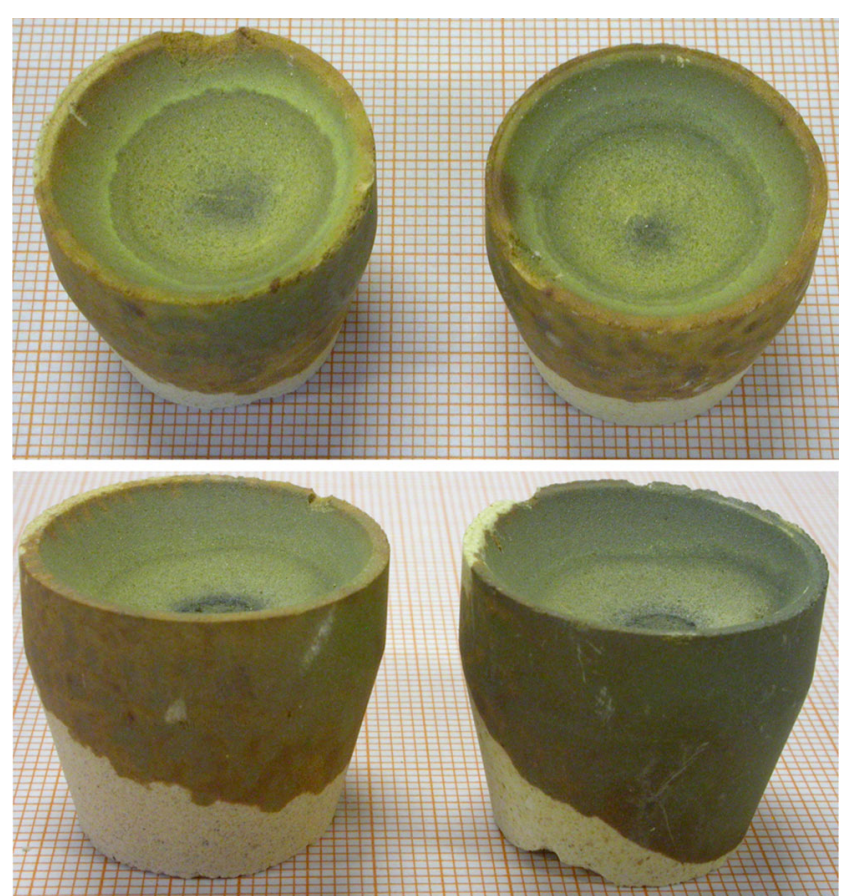

Fig. 5 Aspect of the cupel after the cupellation process. The greenish stain is due to the absorption of $\mathrm{Pb}$ and base metals oxides

disappears and the melted mass remains, gleaming and still (Fig. 3). Figure 4 shows the typical aspect of the beads obtained in this way.

At the end of the process, the cupel turns greenish due to the absorption of $\mathrm{Pb}$ and base metal oxides (Fig. 5). The absorption of oxides occurs among most of the section, as shown in Fig. 6. In the same figure, the acquisition positions of EDS spectra and the semi-quantitative results are also reported. Interestingly enough, a high $\mathrm{Pb}$ concentration and a significant amount of $\mathrm{Cu}$ are detected even into the cupel, which gives evidence of the efficacy of the absorption process. Silver is identified in the region where the bead has touched the cupel. In this area, the EDS microanalysis cannot reveal $\mathrm{Au}$ concentrations lower than $1 \%$ in weight, also because of the concurrent presence of $\mathrm{Pb}$. As a consequence, the presence of $\mathrm{Au}$ is not to be excluded - at least in this area, where it could be associated with Ag. In this case, a common error regarding the final measurement of the gold titer would occur, due to the absorption of gold by the cupel.

The final aim of the cupellation process is to obtain a binary gold-silver alloy, and it is achieved only if the requirements about the weight of inquarted lead and silver are satisfied and the oxide formation occurs correctly, with the appropriate oxygen contribution. At this stage, the operator's skill is fundamental.

However, it must be pointed out that if the alloy contains also $\mathrm{Pt}, \mathrm{Pd}, \mathrm{Ir}, \mathrm{Rh}, \mathrm{Ru}$ and $\mathrm{Os}$, these elements remain in the bead together with $\mathrm{Au}$ and $\mathrm{Ag}$. Ir, Rh, Ru and Os concentrate mainly at the bottom of the bead. In this work, this possibility is not considered and the details about how to deal with this case are not given [4].

In order to examine the microstructure of the bead, some SEM observations have been performed on its surface and metallographic sections.
Fig. 6 The cupel section is mainly saturated with oxides. The chemical composition in the four positions marked by the arrows has been determined by EDS. This technique provides for semiquantitative results. The element concentration changes from cupel to cupel. $\mathrm{Ni}$ and $\mathrm{Zn}$ are other frequently detected elements. Of course, the results can change from bead to bead
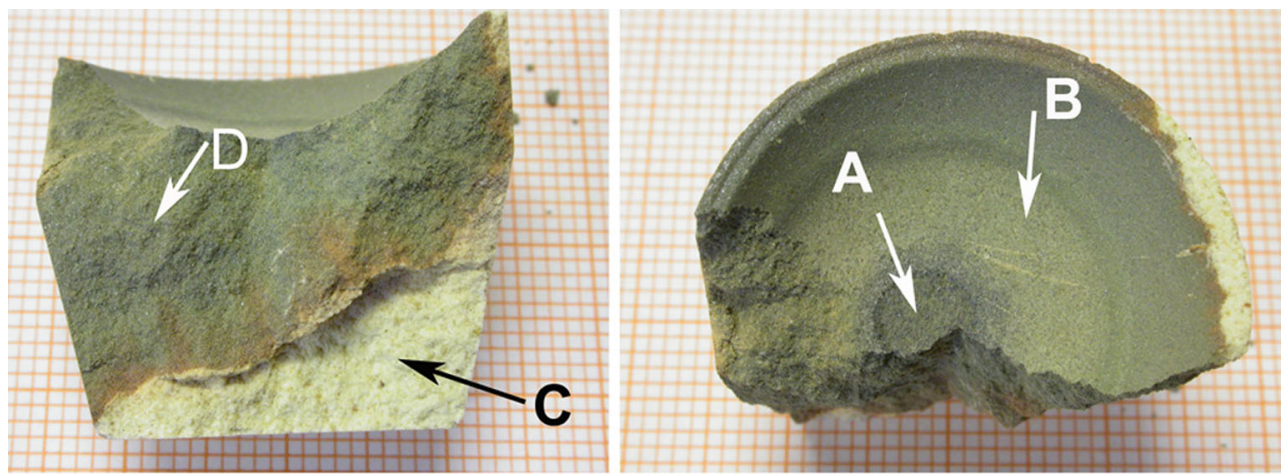

\begin{tabular}{|l|l|l|l|l|}
\hline & \multicolumn{5}{|c|}{ Weight \% } \\
\hline & Point A & Point B & Point C & Point D \\
\hline $\mathbf{O}$ & 35.62 & 40.87 & 45.79 & 36.05 \\
\hline $\mathrm{Na}$ & 0.17 & - & 1.22 & - \\
\hline $\mathrm{Mg}$ & 36.08 & 52.14 & 45.43 & 31.11 \\
\hline $\mathrm{Si}$ & 1.20 & - & 6.18 & 2.80 \\
\hline $\mathbf{F e}$ & 0.30 & 0.37 & - & 0.18 \\
\hline $\mathbf{C u}$ & 0.82 & 0.62 & - & 0.83 \\
\hline $\mathbf{A g}$ & 0.40 & - & - & - \\
\hline $\mathbf{P b}$ & 25.41 & 6.00 & - & 28.62 \\
\hline $\mathbf{C a}$ & - & - & 1.37 & 0.42 \\
\hline
\end{tabular}


The upper part of the bead shows grains whose size changes significantly from specimen to specimen (Fig. 7). This behaviour could be reasonably ascribable to different causes, such as the dissimilar content of $\mathrm{Ag}$ and $\mathrm{Au}$ of the beads, the different solidification rates and the presence of trace elements which act as solidification nuclei. Carbon-rich residues are also detected on the surface.

The bottom of the bead, which touches the cupel, appears rough (Fig. 8), due to the imprint left by the granules of magnesium oxides of the cupel. Lead-base residues and other
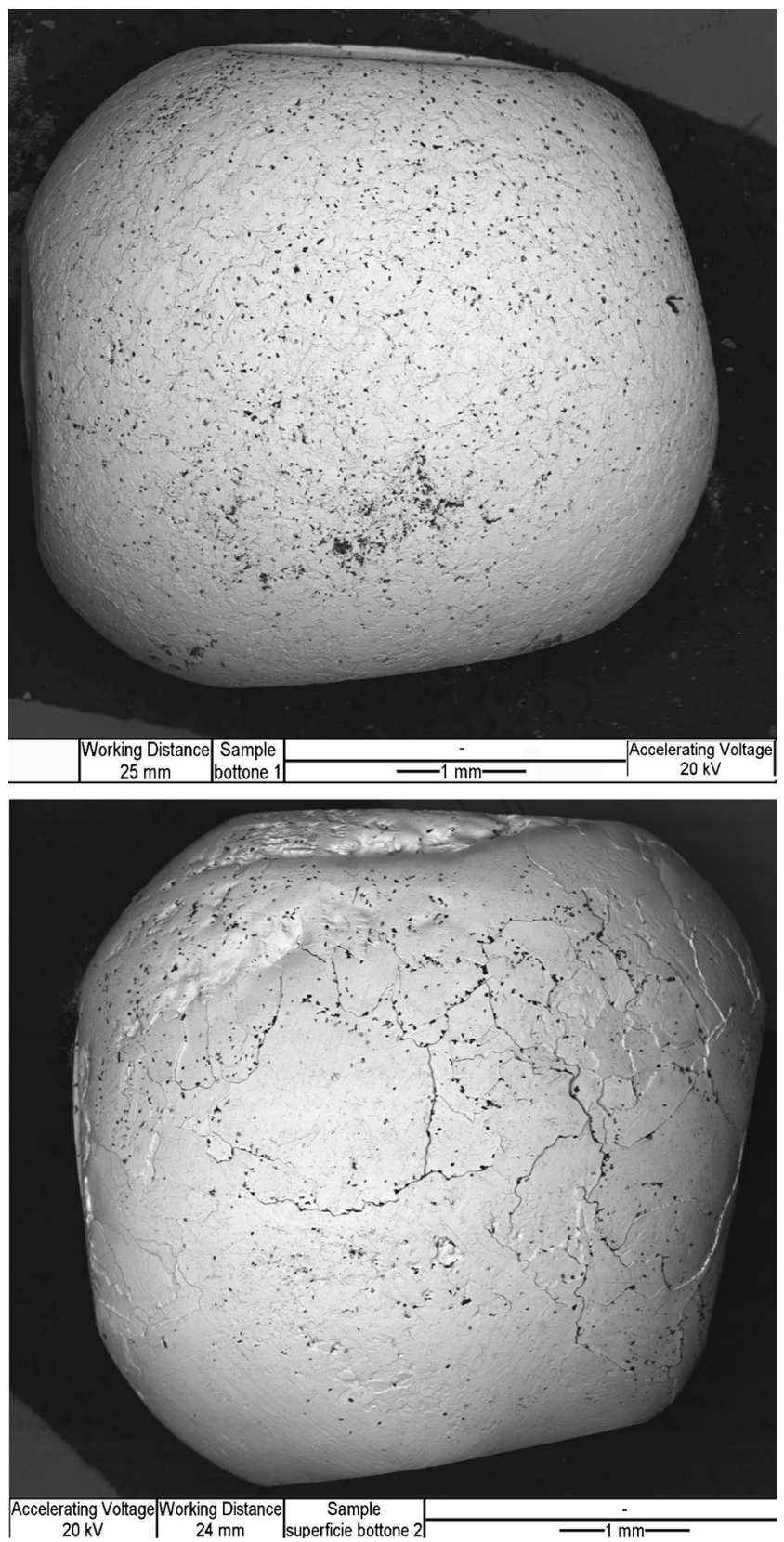

Fig. 7 SEM, backscattered electron image (BEI). Surface of the two beads. Different grain sizes are visible. The small dark particles are carbon-rich residues kind of oxides are found on this side of the bead, as detected by EDS, despite the brushing performed by the operator according to the procedure. This means that the surface cleaning is never accomplished. However, these residues are thought to be removed almost completely by the subsequent partition stage, as they are very superficial and the acid sweeps them away very easily. Recent studies support this idea,

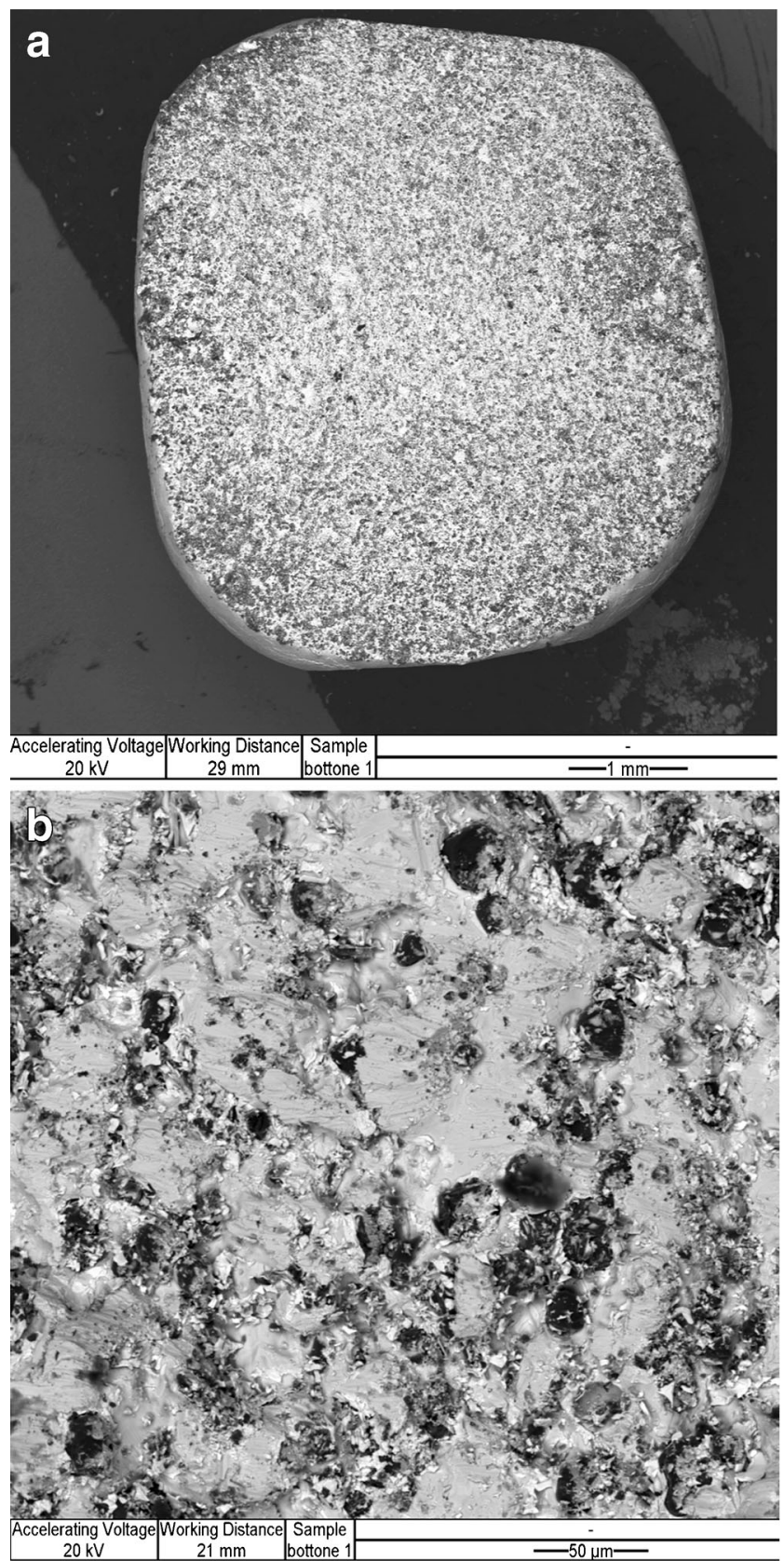

Fig. 8 SEM, backscattered electron image (BEI). a Lower surface of the bead. The surface is rough due to its physical contact with the cupel. Many oxides are steeped in it, even though the bead has been brushed, as per procedure. $\mathbf{b}$ Detail of the bottom of the bead. Oxides, residues of the cupel, scales of lead oxides (white areas) and carbon-rich residues are left despite brushing 


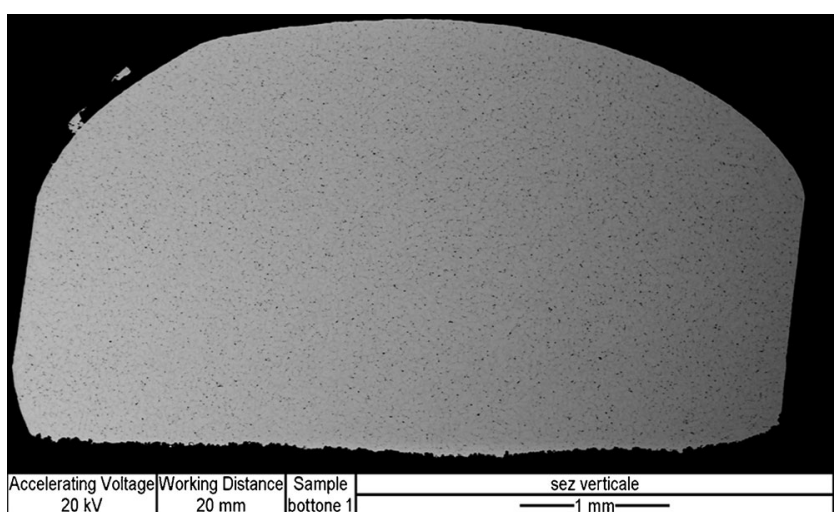

Fig. 9 SEM backscattered electrons image (BEI). Polished vertical metallographic section of the bead seen in the upper part of Fig. 7. Its microstructure is homogeneous, and shows a fine-net silver micro-segregation

showing that the cleaning of this side of the bead can cause only minor measurement errors [5]. However, the operator must be aware of that.

Figure 9 shows the aspect of a vertical section of the bead, perpendicular to the supporting plane of the cupel.

When using the backscattered electron signal of the SEM, a micro-segregation of Ag appears (Figs. 9, 10 and 11). The Ag weight concentration measured by EDS microanalysis along the segregation bands ranges between 74 and $76 \%$ and decreases to about $70 \%$ outside the segregation bands. Obviously, the concentrations reported here concern the bead considered as an example and are a function of the weight of the inquartation Ag used. As a consequence, they change from specimen to specimen.

Small isles mainly made of copper and silver oxides are also observed (Figs. 12 and 13). The horizontal section of the bead shows the same microstructural characteristics as the vertical one.

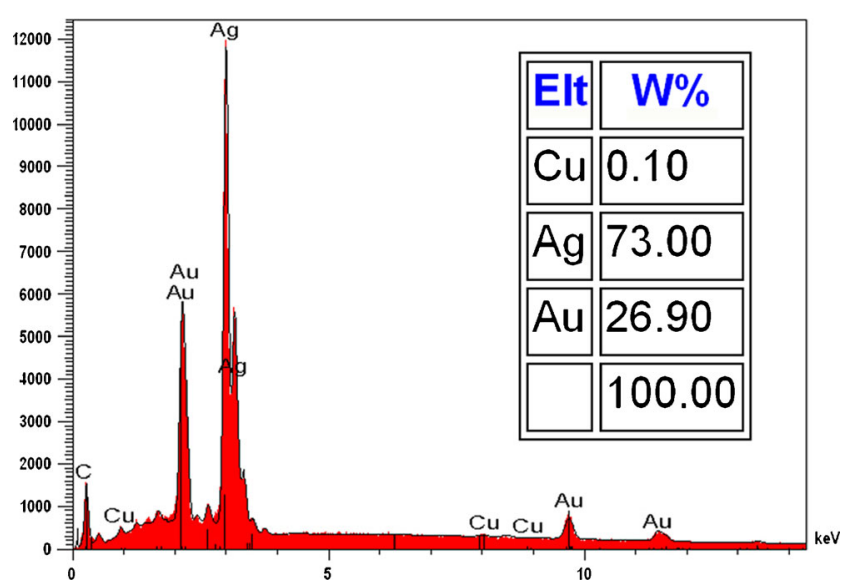

Fig. 10 EDS spectrum acquired on the metallographic section of Fig. 9. The corresponding semi-quantitative chemical analysis is given in the table. The bead contains $\mathrm{Cu}$. The weight ratio $\mathrm{Ag} / \mathrm{Au}$ is about 2.7, which is appropriate, as it should range between 2 and 3. Results change from bead to bead. The presence of other trace elements cannot be excluded, due to the relatively low sensitivity of the EDS technique

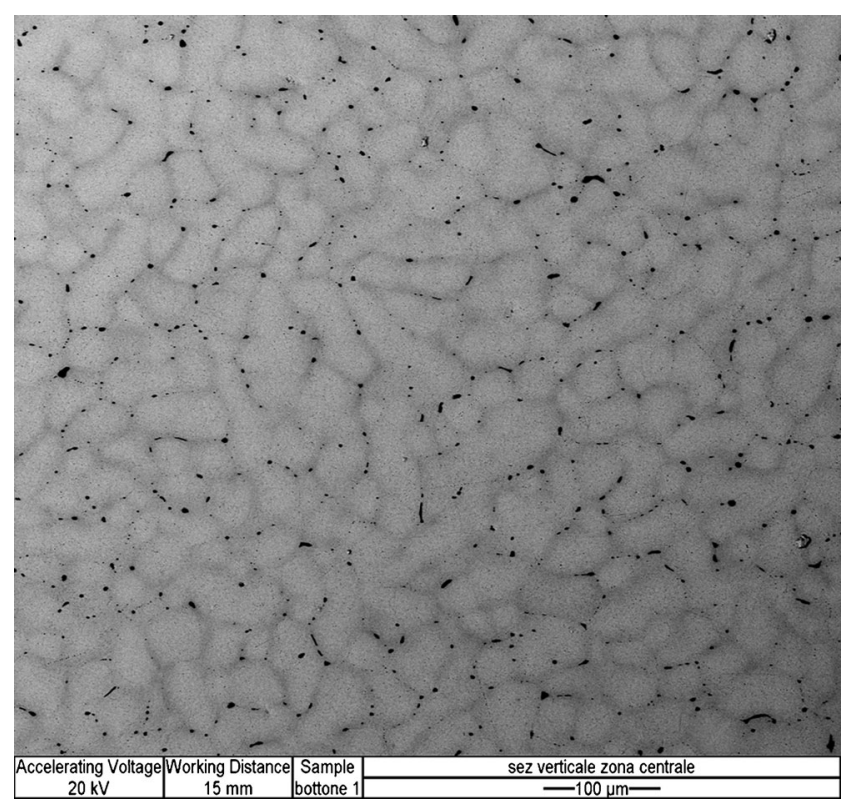

Fig. 11 SEM backscattered electrons image (BEI). Detail of Fig. 9. The fine network due to the micro-segregation of silver is visible. The weight concentration of silver on the boundaries of the net is about $75 \%$. The small dark isles are composed of $\mathrm{Cu}$ and $\mathrm{Ag}$ oxides. See their detail in Fig. 12. The morphology of segregation changes from bead to bead

At the end of this section, it is important to notice that the bead is not a homogeneous and pure gold-silver alloy, as expected, but contains some oxides on the bottom surface and inside its section.

\section{Cornet stage}

The bead is hammered, annealed and rolled to a thin strip. Then, the rolled section is flame annealed and

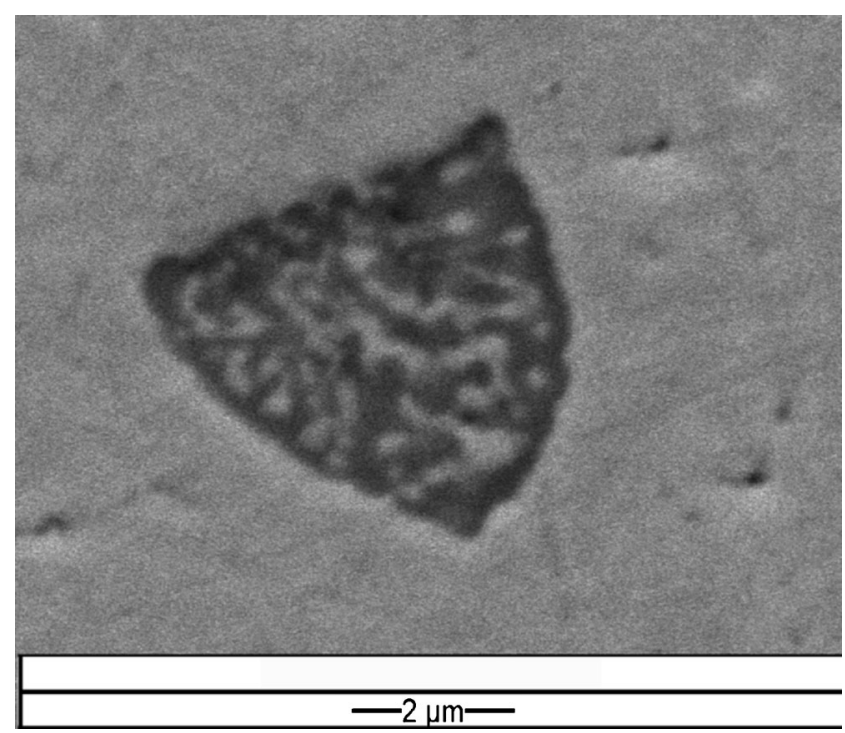

Fig. 12 Detail of one of the dark isles (spots) of Fig. 11, made of Cu and $\mathrm{Ag}$ oxides (see the correspondent EDS spectrum in Fig. 13) 


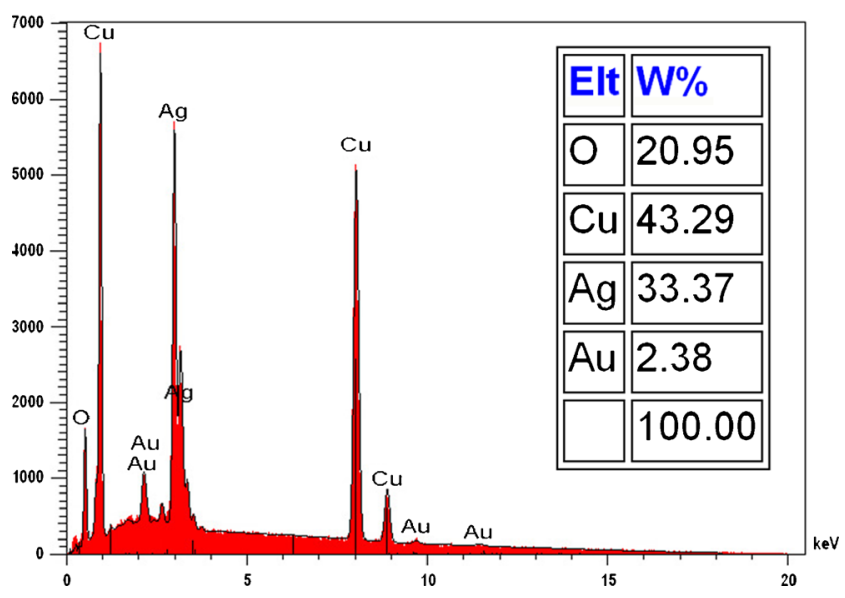

Fig. 13 Typical EDS spectrum acquired on the dark isles visible in Figs. 11 and 12. They are mainly made of $\mathrm{Cu}$ and $\mathrm{Ag}$ oxides

subsequently rolled up to a cornet-like shape (Fig. 14). The rolling must not be too tight, so as to allow the wettability of the whole surface. Furthermore, particular attention must be paid in order to keep the previous bottom of the bead - the one contacting the cupel, to the outside. By doing this, the oxides seen on this side of the bead will be on the outer surface of the cornet. Now, the cornet is ready to be put into an acid solution in the following partition process.

An analysis by TEM has been performed on thin foils obtained from the surface of the annealed strip. The TEM thin foils are prepared by thinning the material by means of the socalled dual beam system (FEG-FIB) available in a focused ion beam apparatus [2]. Figure 15 shows the surface of the strip where the thin foils have been obtained. The presence of some grains in relief and the dispersion of fine round pores give evidence that annealing has taken place.

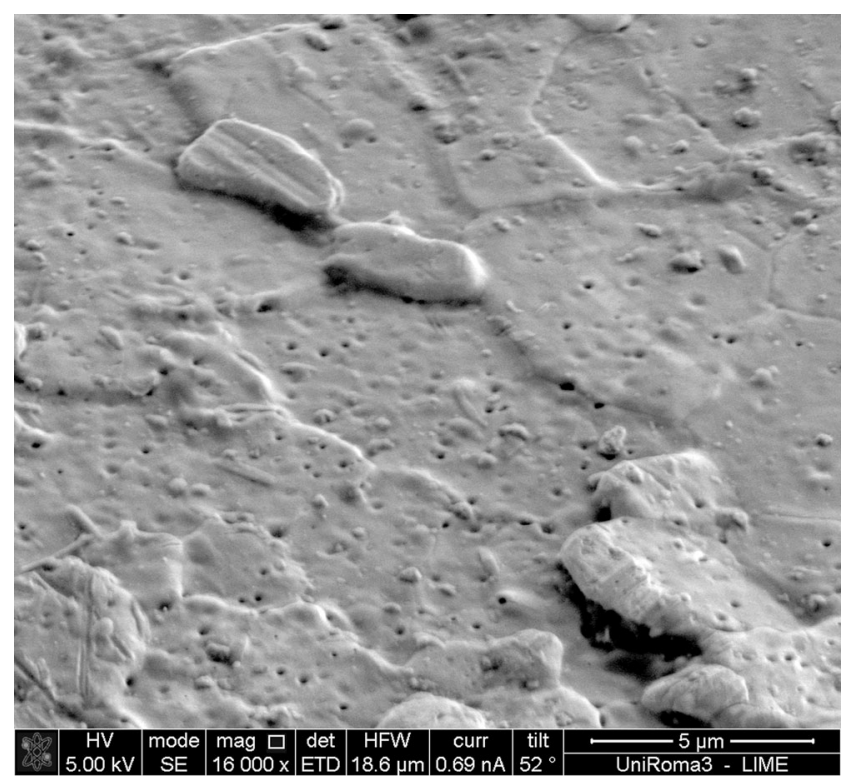

Fig. 15 SEM image of the surface of the work-hardened strip after flame annealing. The re-crystallization reveals the grains of the material. In addition, a dispersion of small voids is observed

The effect of annealing on re-crystallization is clearly visible. The nano-voids created during dislocation coalescence characterizing the surface also affect the bulk, down to about $3 \mu \mathrm{m}$ (Figs. 16 and 17). They are present in this zone because the plastic deformation of the metal is higher in this thin layer of the section, due to the rolling process.

The dislocation density decreases dramatically after flame annealing (Fig. 18), which is also supported by electron diffraction, as well as the twin crystals presence (Fig. 19). These observations show that the cause of the surface nano-voids is due to the re-absorption of dislocations.
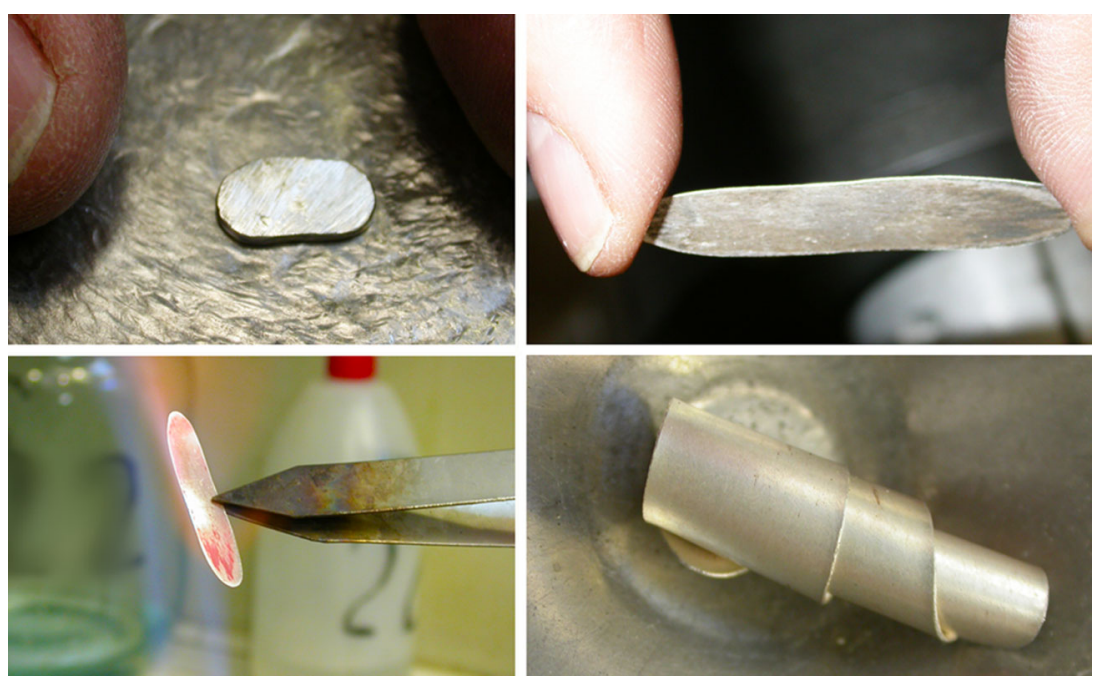

Fig. 14 The four stages of the cornet preparation are here represented. First the bead is hammered, flattened and rolled to a thin strip (top right), then flame annealed by means of a Bunsen apparatus and cornet shaped by hand 


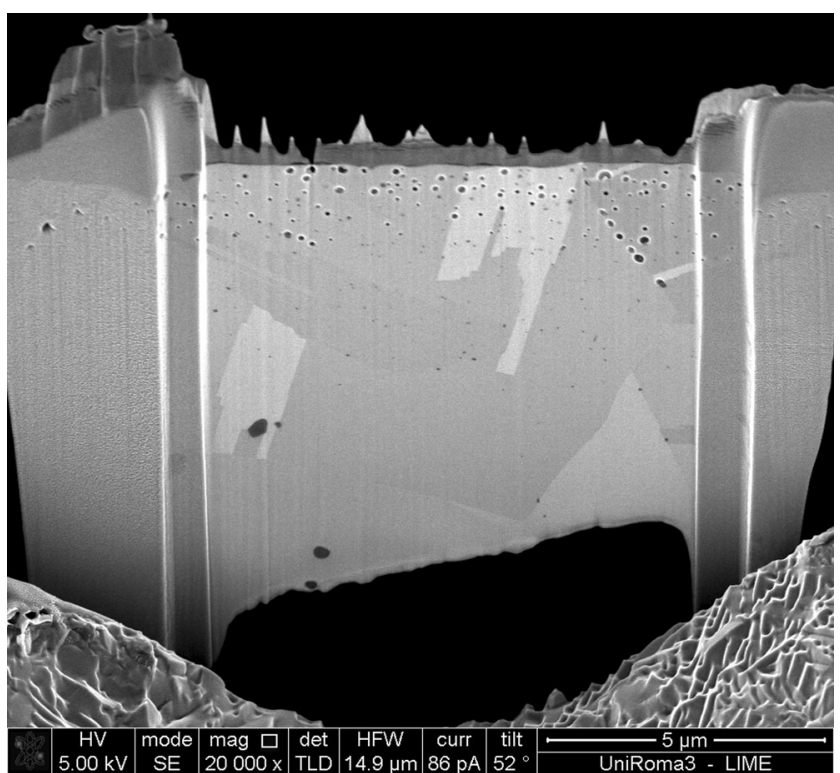

Fig. 16 At the end of the thinning procedure, the thin foil is pulled out of the specimen, ready to be analysed by TEM. The surface of the strip is the upper part of the thin foil

\section{Parting stage}

The parting stage allows the separation of gold from silver, providing a cornet made of gold only. The process occurs in two stages, by keeping the cornet in boiling nitric acid. The first stage makes use of nitric acid in $22^{\circ}$ Bè (bè degrees) aqueous solution, the second one of nitric acid in $32^{\circ}$ Bè aqueous solution (Fig. 20).

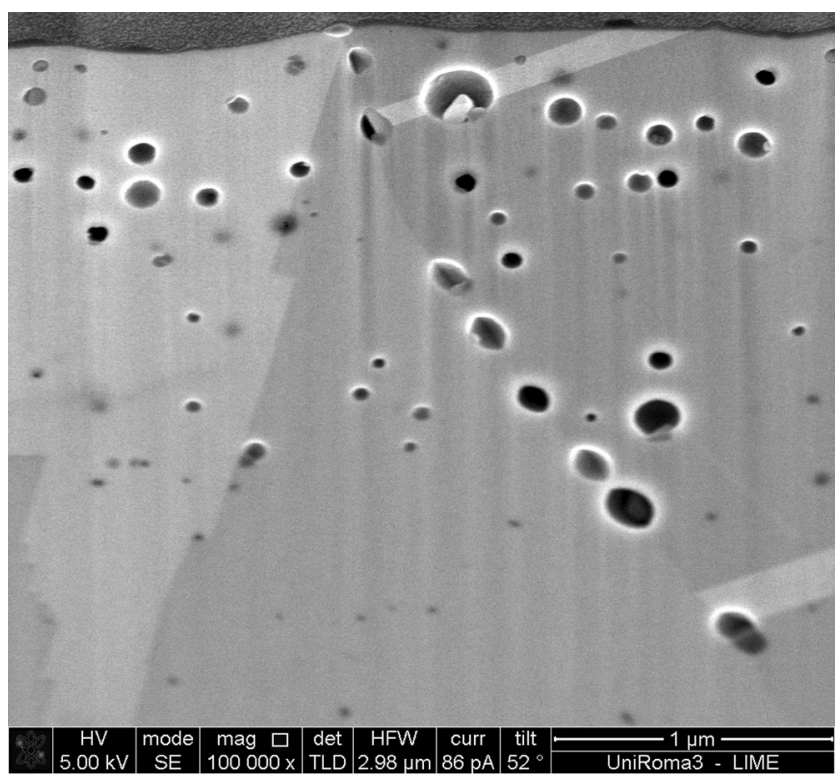

Fig. 17 SEM image of the thin foil obtained from the strip after flame annealing. See the grain re-crystallization and the presence of round nanovoids down to $3 \mu \mathrm{m}$ in depth from the surface
At the end of the process, a brownish cornet—very difficult to handle, is obtained (Fig. 21). This cornet contains only gold. If too much silver, with respect to the initial specimen gold content, is added in the cupellation process, the cornet breaks into small pieces or even reduces to powder during partition. The microstructural evolution of the material during partition has long been unexplained. In fact, partition is simplistically referred to as a process in which silver is removed by means of nitric acid, which leaves only gold atoms inside the cornet. This description is not enough to describe thoroughly what happens. The reason why the cornet preserves its initial geometric shape (Fig. 21) is not clear. Since it is made of a quite homogeneous binary gold-silver alloy, a selective dissolution of silver should lead to a powder-like gold precipitation at most. Therefore, the reason why the cornet keeps its geometrical shape has been investigated by performing microstructural studies after partition.
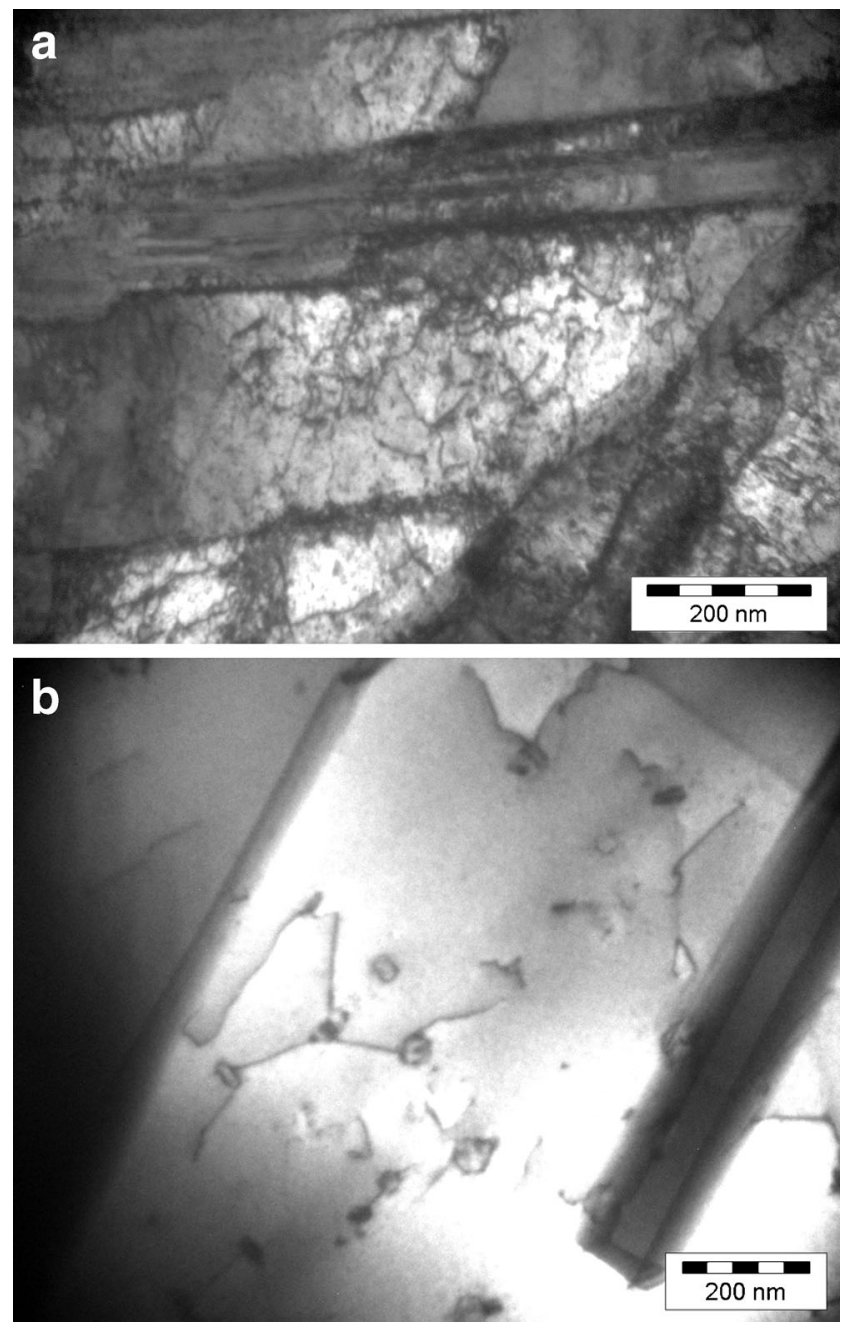

Fig. 18 TEM images. a Detail of the microstructure of the workhardened strip. b Detail of the strip after flame annealing. The material re-crystallization causes a significant decrease in dislocation density. Very few dislocations and twin crystals appear in this image 


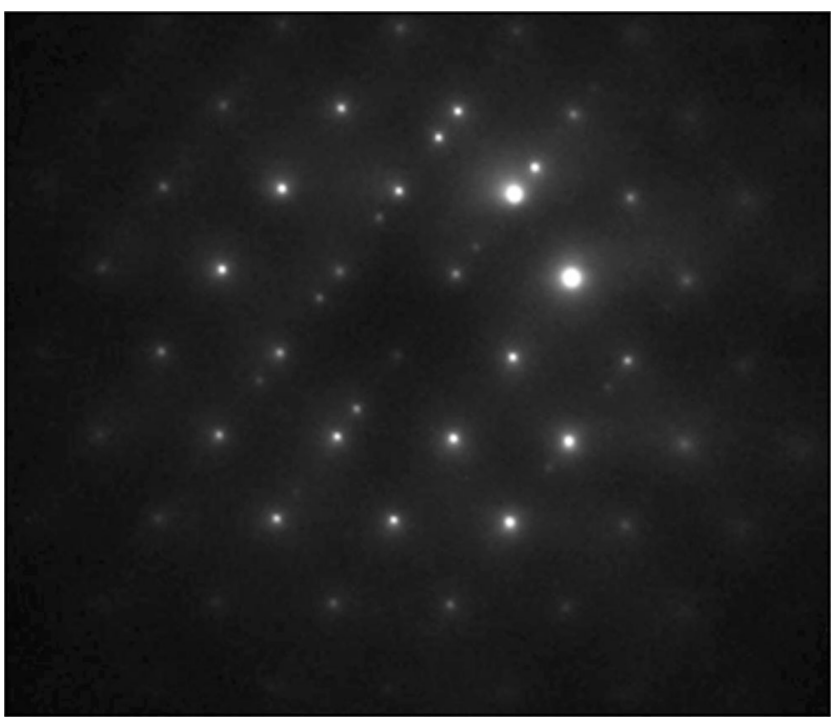

Fig. 19 The electron diffraction pattern corresponding to the area in Fig. $18 \mathrm{~b}$ confirms the considerable decrease in the dislocation density (the diffraction spots are dot-like and not elongated) and the presence of twin crystal, proved by twin spots next to the main ones

Figure 22 shows a detail of the cornet surface after partition (dark brown cornet in Fig. 21). The surface has the typical appearance of the nanoporosity obtained after dealloying of a Ag-Au alloy [6-8]. This microstructure is characterized by a considerable isotropy, not only at the surface of the cornet but also inside it (Figs. 23 and 24). The dealloying process and the microstructure of nanoporous gold have been studied and a mechanism of nanoporosity development has been proposed [9-17].

Another microstructural feature which turns out after the partition process is highlighted in Figs. 25 and 26. Along the cracks which reveal the inner part of the cornet, intergranular surfaces or better still the surfaces corresponding to the previous grain boundaries of the annealed strip are visible. This means that the transformation that occurred during partition

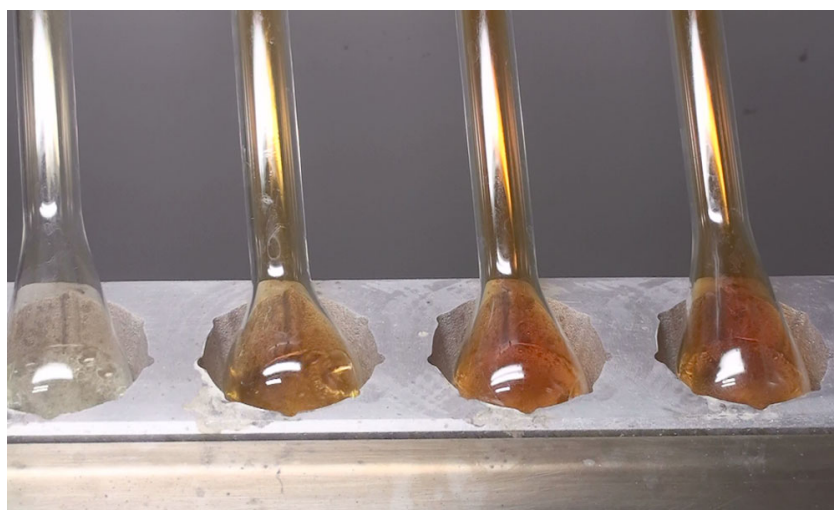

Fig. 20 Dissolution of silver during the first stage of partition, in $22^{\circ}$ Bè boiling nitric acid. The amber fumes are produced by the dissolution of silver. The boiling acid is visible at the bottom of the flask
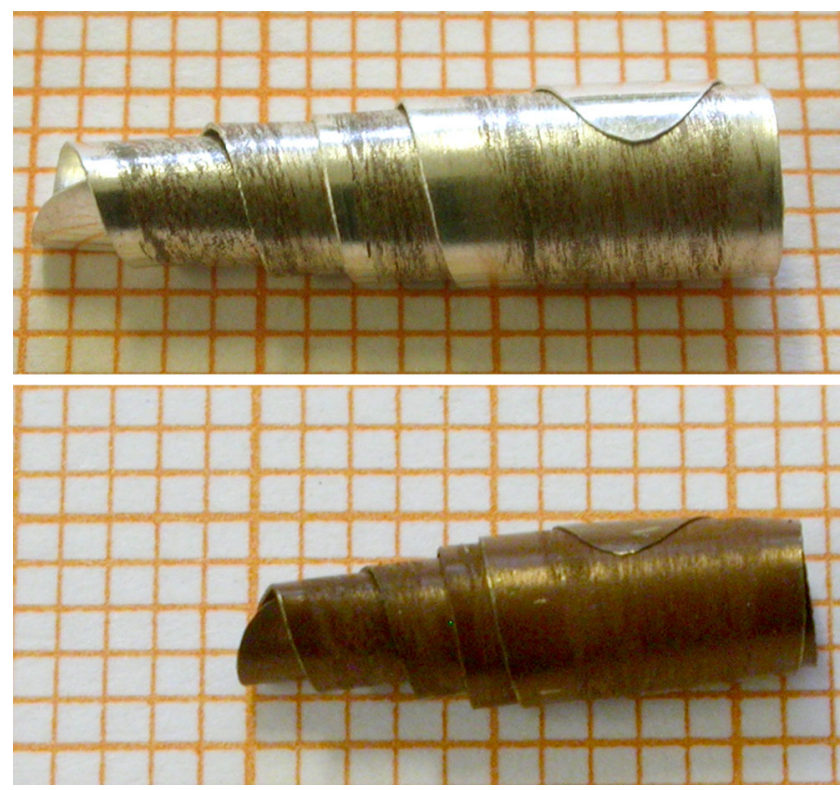

Fig. 21 The same cornet before and after partition is shown in the upper and lower part of the figure, respectively. See the size reduction that the cornet undergoes during the process. After partition, the cornet becomes typically brown, but preserves its initial shape

has taken place on a nanometric scale, preserving memory of larger sized structures such as the initial crystal grains. The gold atom movement giving rise to the nanoporous gold has occurred 'locally', without involving wider scale diffusion phenomena. This aspect is perfectly in agreement with the model describing the nanoporous gold genesis. Furthermore, the shrinkage of the cornet which preserves its morphology (Fig. 21) is a typical feature of the dealloying process [7].

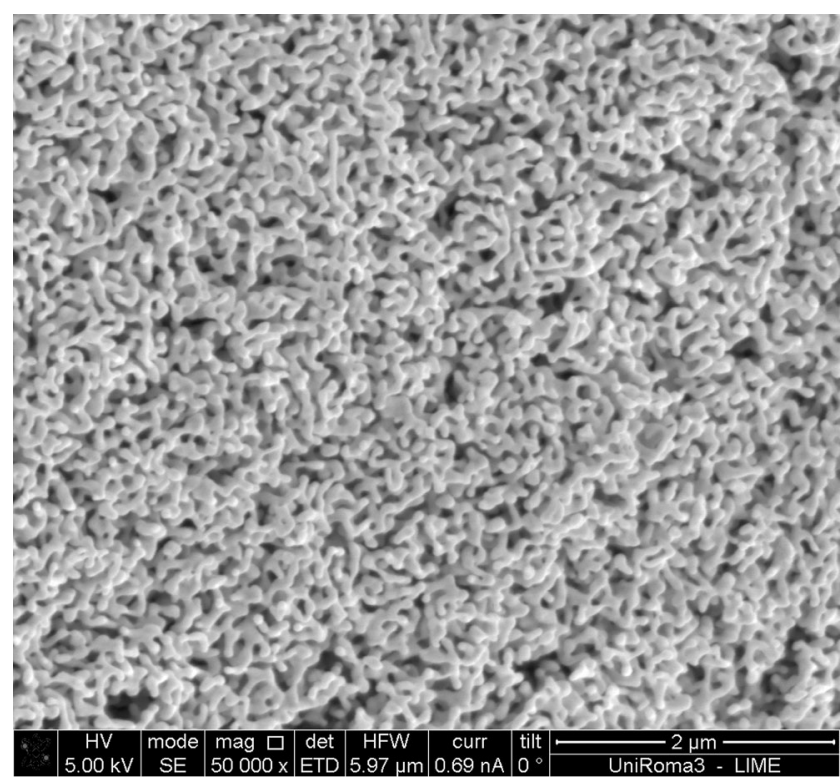

Fig. 22 Cornet surface after partition (brown cornet in the lower part of Fig. 21). A granular structure is observed, whose granule size is uniform 


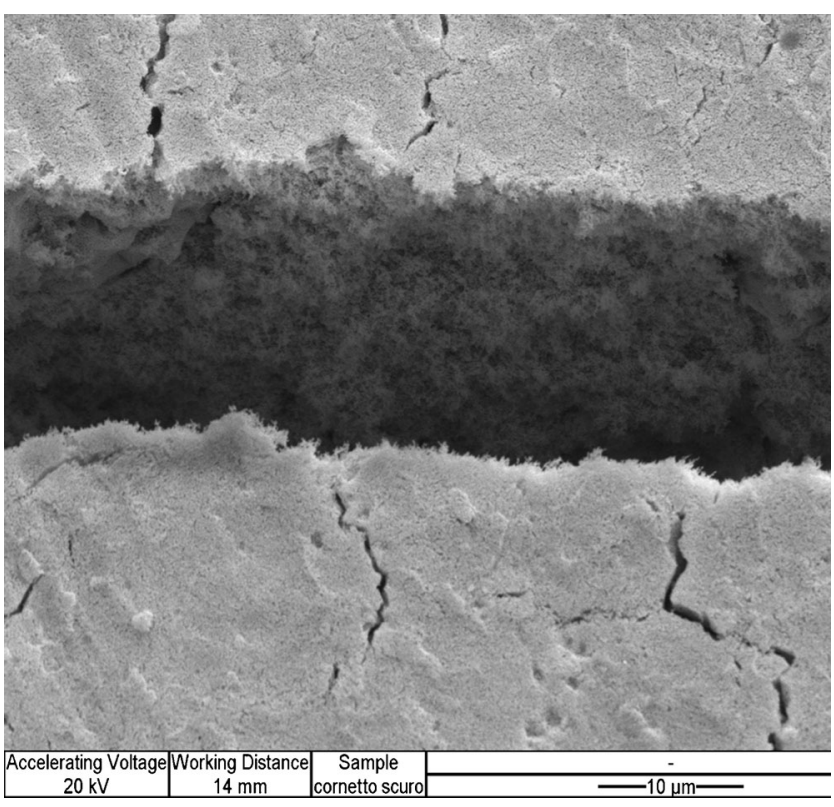

Fig. 23 SEM image. Fractures on the cornet surface after partition. The isotropy of nanoporosity is seen also inside the cornet

In the light of the dealloying process, the geometry of the nanoporous gold (pore size, ligament size, gold cluster size) depends on the process of parting and on the initial silver-gold ratio. This means that good results are possible only if all the process parameters are respected. Furthermore, the final microstructure of the cornet after partition may change from a laboratory to another, due to slightly different equipments and procedures. It would be interesting to know if suggestions can be given in order to get the best results, for example reducing cracks in the nanoporous structure of the cornet.

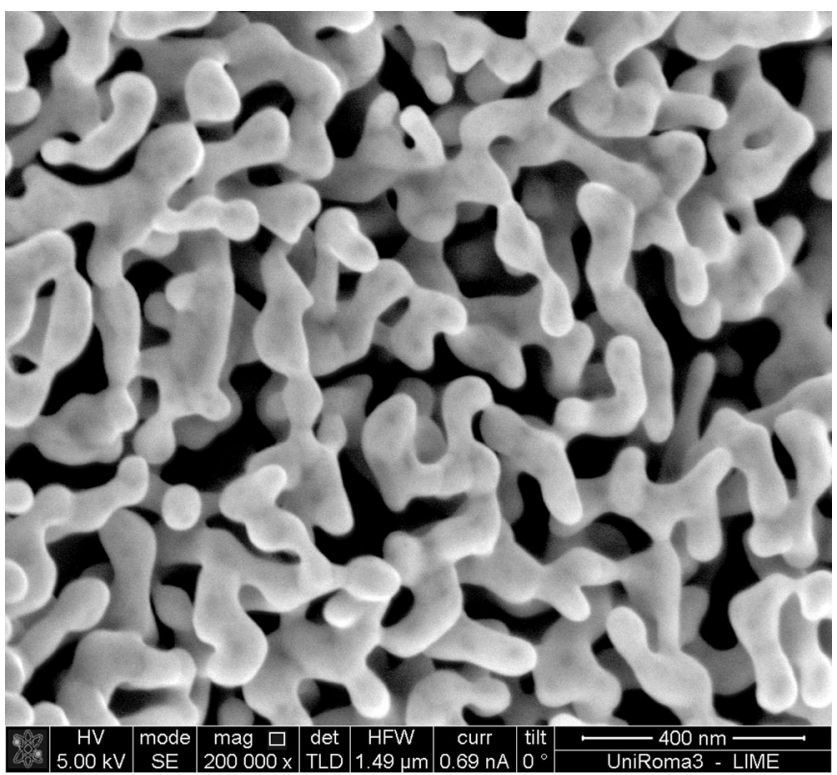

Fig. 24 Detail of the cornet microstructure after the partition process. A nanoporous morphology characterizes the whole specimen

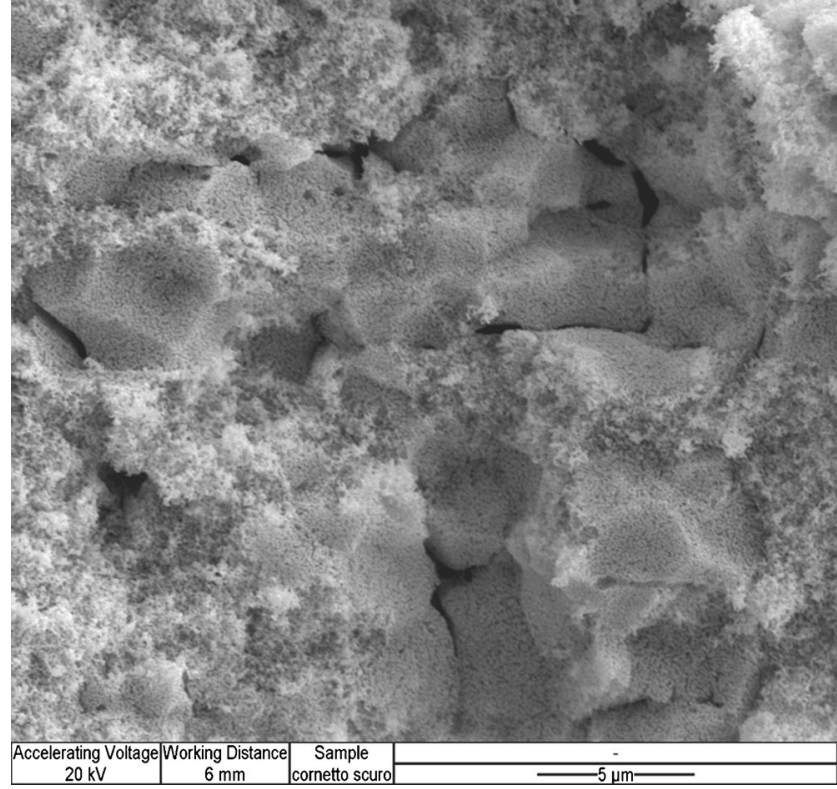

Fig. 25 SEM image. By breaking the cornet after partition, it is possible to detect the previous grain structure. The transformation of the material into a sponge structure has occurred on a nanometric scale, preserving the memory of the previous crystal grains. The grains appear detached from one another

In order to better understand the microstructure of the nanoporous cornet, a TEM thin foil has been prepared.

Figures 27 and 28 are TEM images of the nanoporous gold at different magnification. The nanoporous gold shows an inner fragmentation into gold nanocrystals, just a few nanometers sized. The nanocrystals are separated by twin crystals boundaries, as shown by selected area electron diffraction

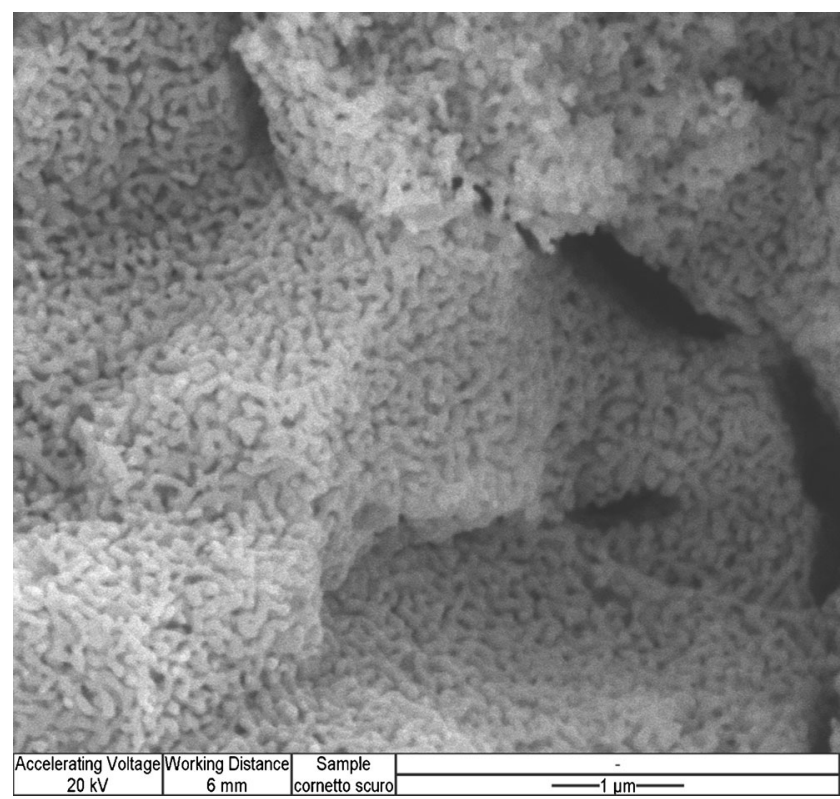

Fig. 26 SEM image. Detail of Fig. 25 showing an ex grain boundary region 


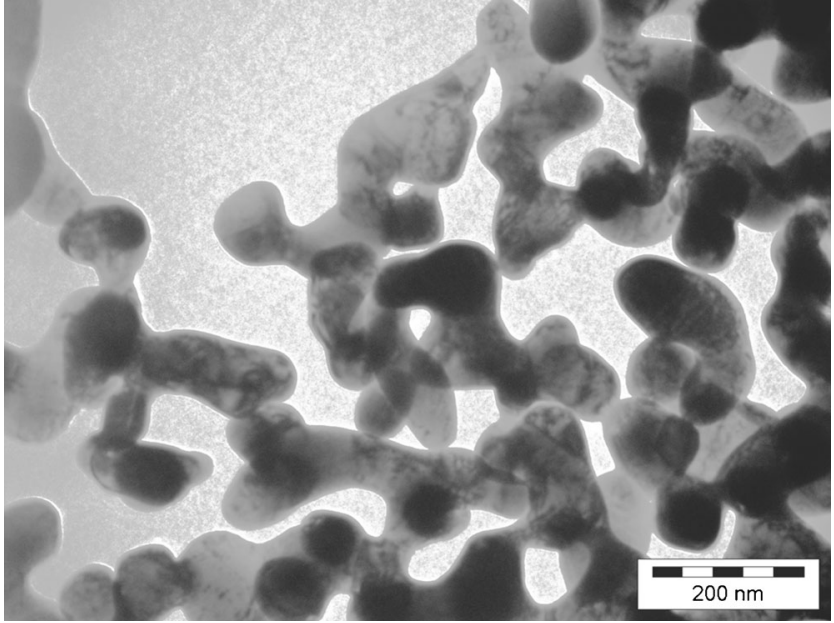

Fig. 27 TEM image of the nanoporous microstructure

(Fig. 29), which means that the nanoporous gold is composed of a pure gold nanocrystals cluster.

The fact that the cornet (Fig. 21) has a nanoporous microstructure explains the reason for its brown colour. This optical characteristic originates from the nanoscale morphology. In general, it can be said that, due to the nanoporosity, new modes of interaction of the light with the gold became important. In particular, interactions involving electronic oscillations called surface plasmons are possible. Furthermore, the gold behaves optically as a metal towards higher wavelengths (in the near-IR region) in comparison with bulk gold. For this reasons, the cornet appears brown in colour [18-22]. This very interesting behaviour of nanoporous gold and gold nanoparticles has been studied also for many different applications, such as monitoring body fluids, new electronic devices and decorative effects [23-31].

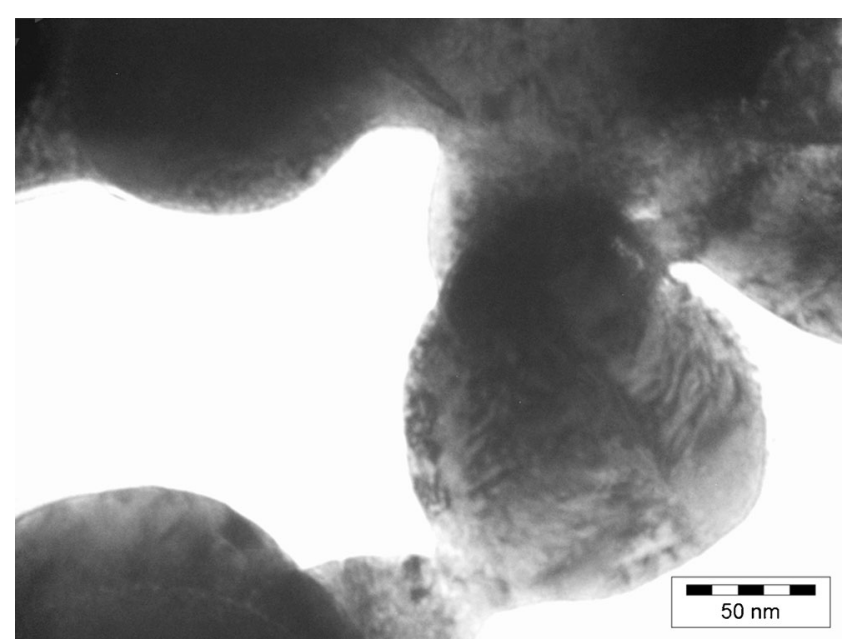

Fig. 28 Detail of the nanoporous microstructure. Electron diffraction can be performed on a selected area (SAD) whose diameter can be reduced down to $20 \mathrm{~nm}$, and whose position can change

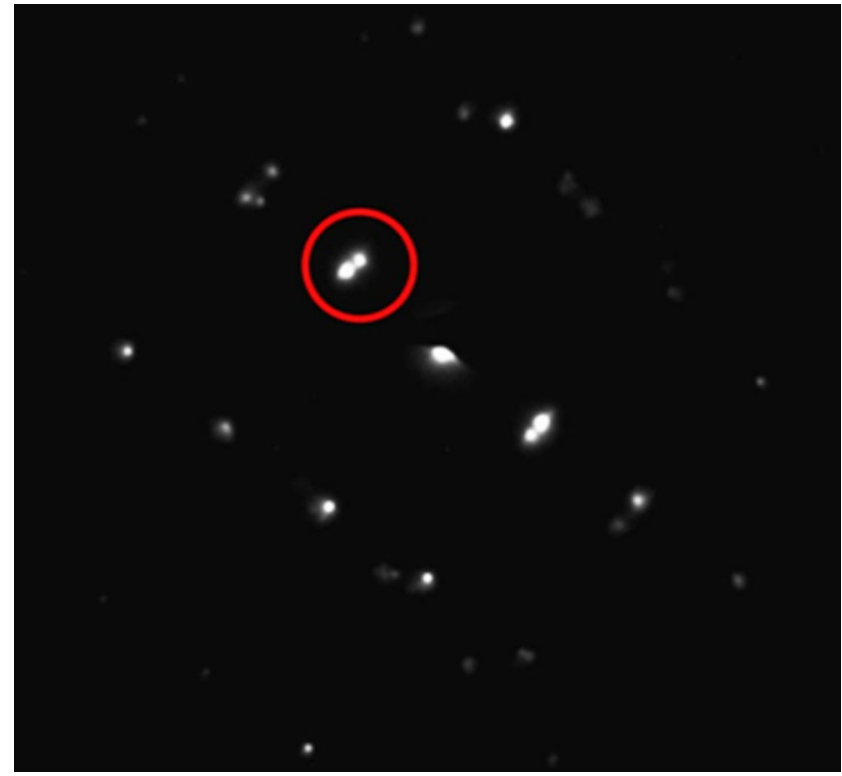

Fig. 29 Selected area diffraction shows that the crystal structure of the sponge is pure gold and is characterized by twin crystals, as proved by the twin spots (see the circle in the SAD image)

The annealing process of the cornet

After the partition process, the cornet is fragile due to its microstructure. At this point, the fire assay procedure entails annealing the cornet to make it easy to handle again. Annealing involves placing the cornet on a cupel which is put into the furnace at $900-9500^{\circ} \mathrm{C}$. At the end of the process, the cornet has the typical gold colour and can be easily handled (Fig. 30). Obviously, this final annealing causes a decrease in its size, which adds to the one already occurred during partition. The nanoporous microstructure disappears in the final cornet.
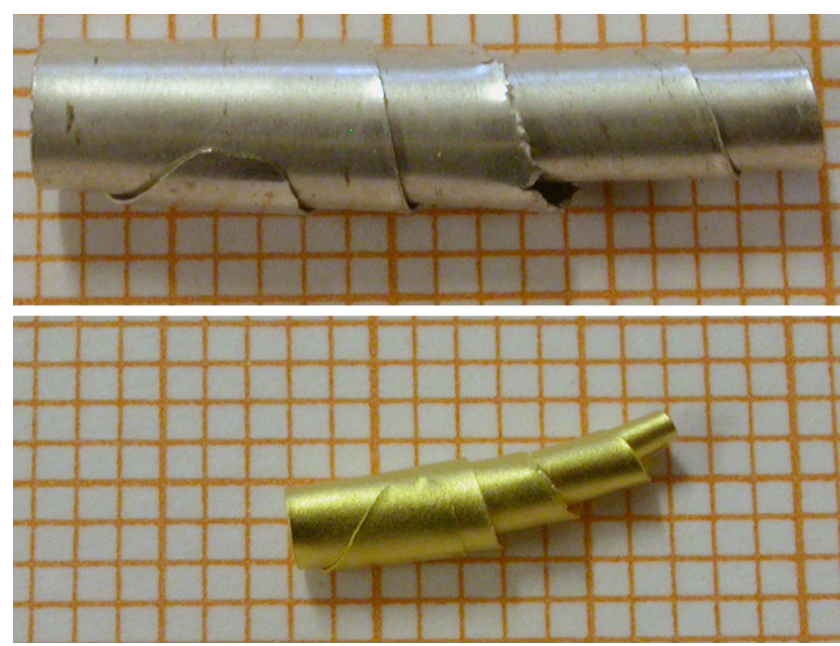

Fig. 30 The same cornet before partition and after final annealing is shown in the lower and upper parts of the figure, respectively 


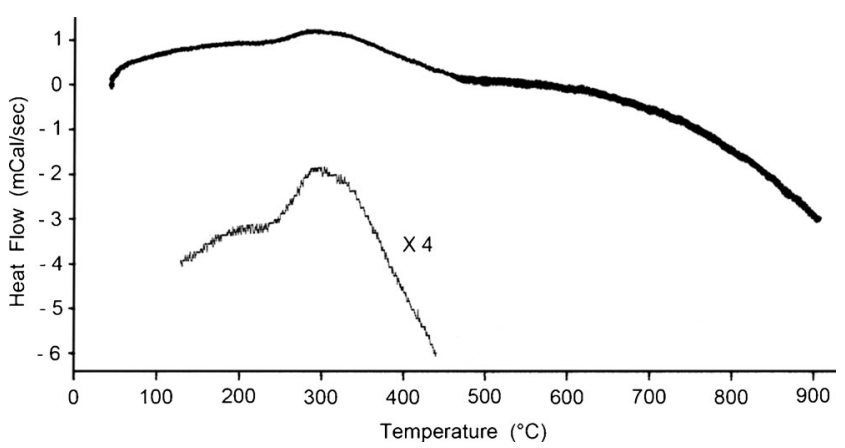

Fig. 31 The calorimetric curve shows only an exothermic reaction between 220 and $350{ }^{\circ} \mathrm{C}$ (see the lower curve, which is a magnification of the upper one). The peak of the exothermic reaction is at about $300^{\circ} \mathrm{C}$

A calorimetric analysis has been performed to define the temperature range in which the process of the nanoporous gold evolution into a bulk structure takes place.

The temperature inside the calorimeter has been increased at a speed of $7{ }^{\circ} \mathrm{C} / \mathrm{min}$ and the specimen has been kept in nitrogen flow. The obtained graph is shown in Fig. 31. This measurement, repeated on other cornets, makes it clear that the nanoporous gold changes its structure at temperatures which are much lower than the gold melting temperature. At a temperature of $500{ }^{\circ} \mathrm{C}$, the cornet already shows the characteristic colour of gold. SEM analyses reveal that at $500{ }^{\circ} \mathrm{C}$ the nanoporous structure is almost completely destroyed for the most part, at least on the cornet surface (Fig. 32).

Even this behaviour of the nanoporous gold is well known. In fact, the most frequently used method to modify the morphology of nanoporous gold has been the thermal treatment

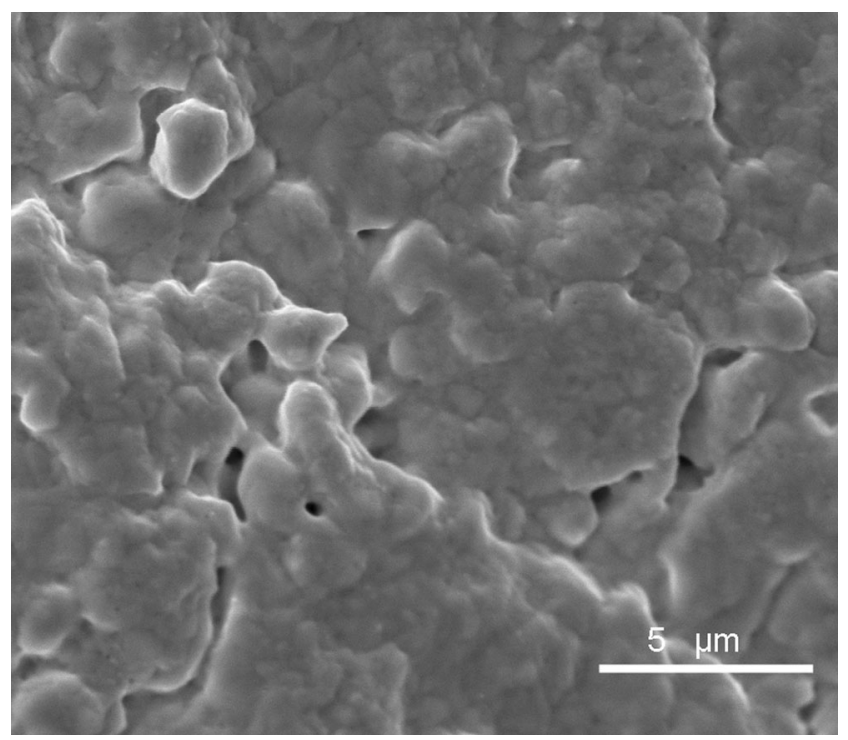

Fig. 32 SEM image. The surface morphology of the cornet after heating at $500{ }^{\circ} \mathrm{C}$ shows that the nanoporous microstructure has disappeared, at least on the surface
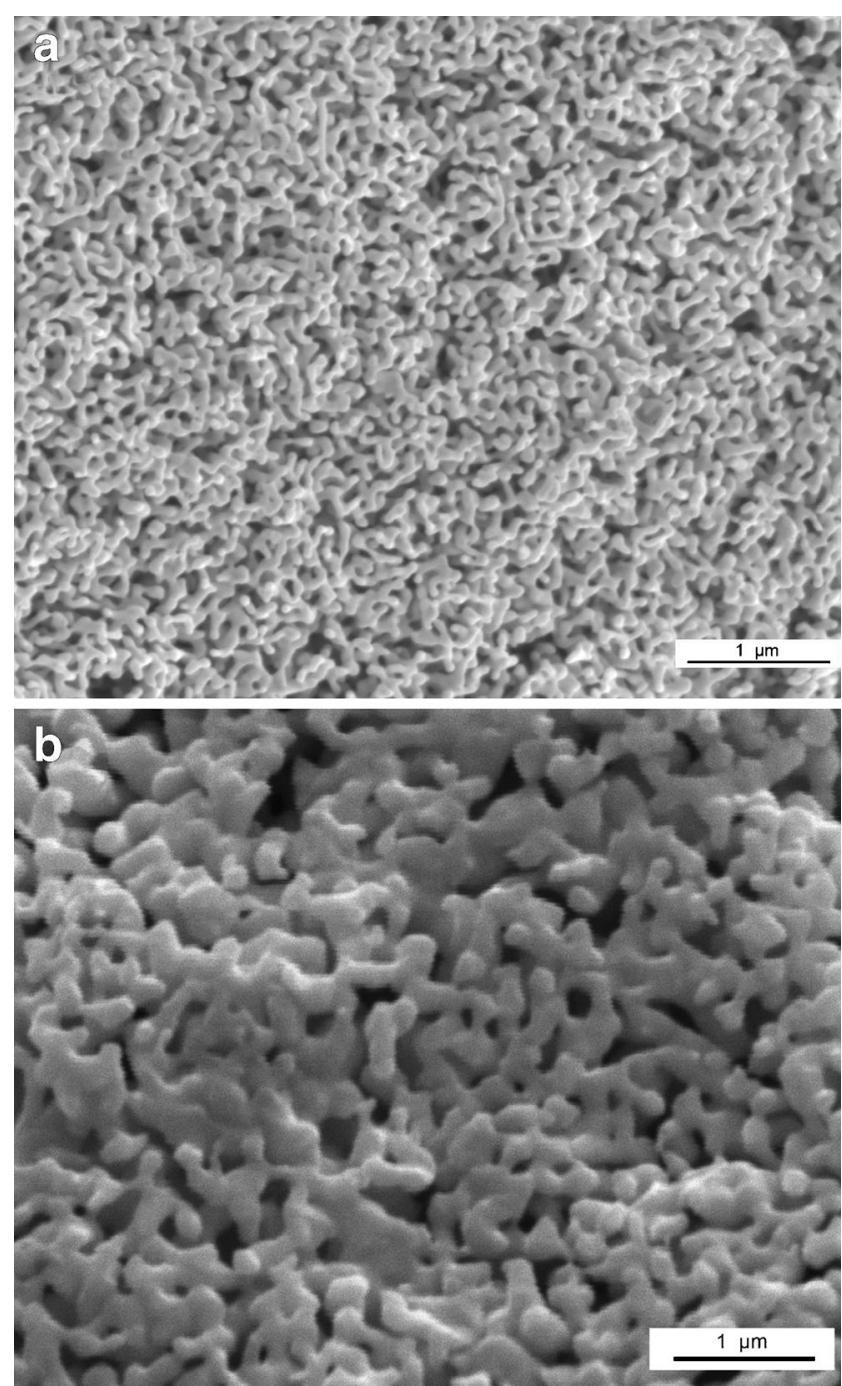

Fig. 33 The figure shows the initial nanoporous surface of the cornet (a) compared with the same surface after heating at $450{ }^{\circ} \mathrm{C}(\mathbf{b})$. This is the typical thermal coarsening of the nanoporous gold which preserves the starting morphology and only increases the features in size

which leads to the coarsening of pores and ligaments [7]. This thermal coarsening preserves the starting pore structure, its only effect being increasing the size of the characteristic features (consider Fig. 33).

The mechanism of thermal coarsening is partly due to the increase in surface diffusion of gold atoms, which leads to an increase in the average pore size. The calorimetric curve (Fig. 31) shows that an exothermic reaction takes place, according to a reduction in energy of all the system. Furthermore, it must be considered that the nanoporous gold is characterized by a surface tension [32] whose release during heating may contribute to the evolution of the microstructure.

The fire assay process comes to an end now. The annealed cornet is now weighed again. The gold concentration of the initial specimen, which weight is known, is therefore computed from the two measurements. 


\section{Conclusions}

This work shows that a process which has been given for granted and well established for ages reveals interesting aspects of the behaviour of precious metals such as gold and silver. Particularly, it is possible to explain how the material evolves during the fire assay and, especially, understand the reasons why the cornet changes colour and shrinks during the partition stage.

What reported here clarifies why all the stages of the procedure must be performed in order to obtain good results. Particularly, the action of lead as a scavenger of base metals and the logic of adding silver in precise amounts during the cupellation stage in order to have the nanoporous gold are understood. Finally, the microstructural analyses reveal the reason why it is necessary to make use of all the well-known working methods in the various phases of the procedure.

The cupellation process appears to be a dealloying process which can be improved thanks to the knowledge of the mechanisms of nanoporosity evolution and nanoporous gold generation, in particular, in order to avoid the cracks inside the cornet which may be responsible for loosing small pieces of material and producing errors in the gold content measurement.

Therefore, the analysts who perform the fire assay test daily can better understand what they usually do and improve the procedure further, in the light of what reported here.

Acknowledgments The authors are very grateful to Dr. Chris Corti for the useful suggestions and discussion of the results here reported. Thanks are due also to Mr. Giovanni Cascione, analyst at $8853 \mathrm{SpA}$ who has prepared the specimens and taken part in the discussion of the results, giving most useful ideas for further reflection.

Open Access This article is distributed under the terms of the Creative Commons Attribution License which permits any use, distribution, and reproduction in any medium, provided the original author(s) and the source are credited.

\section{References}

1. Biringuccio V (1540) De La Pirotechnia. Kessinger, Whitefish, print $\mathrm{n}$ demand

2. Bemporad E, Sebastiani M (2010) Focused ion beam and nanomechanical tests for high-resolution surface characterization: Not so far away from jewelry manufacturing. The Santa Fe Symposium on Jewelry Manufacturing Technology 2010, Eddie Bell (ed.) (Albuquerque: Met-Chem Research, 2005)

3. Smith EA (2003) The sampling and essay of the precious metals 1947, 2nd edn. Met-Chem Research, Albuquerque, Reprinted 2003

4. Raw P (1997) The assaying and refining of gold, a guide for the gold jewellery producer. World Gold Council,

5. Metalor: http://www.lbma.org.uk/assets/17_Cassagne.pdf Accessed 04 July 2013

6. Cortie MB, Maaroof AI, Stokes N, Mortari A (2007) Mesoporous gold sponge. Aust J Chem 60(70):524-527

7. Seker E, Reed ML, Begley MR (2009) Nanoporous gold: fabrication, characterization, and applications. Materials 2:2188-2215
8. Wittstock A, Biener J, Erlebacher J, Baumer M (eds.) (2012) Nanoporous gold: from an ancient technology to a high-tech material. Royal Society of Chemistry.

9. Erlebacher J, Sieradzki K (2003) Pattern formation during dealloying. Scr Mater 49:991-996

10. Erlebacher J, Aziz MJ, Karma A, Dimitrov N, Sieradzki K (2001) Evolution of nanoporosity in dealloying. Nature 410:450-453

11. Lu X, Balk TJ, Spolenak R, Arzt E (2007) Dealloying of Au-Ag thin films with a composition gradient: influence on morphology of nanoporous Au. Thin Solid Films 515:7122-7126

12. Eilks C, Elliott CM (2008) Numerical simulation of dealloying by surface dissolution via the evolving surface finite element method. J Comput Phys 227:9727-9741

13. Fujita T, Qian L, Inoke K, Erlebacher J, Chen M (2008) Threedimensional morphology of nanoporous gold. Appl Phys Lett 92: 251902

14. Zinchenko O, De Raedt HA, Detsi E, Onck PR, De Hosson JTM (2013) Nanoporous gold formation by dealloying: a Metropolis Monte Carlo study. Comput Phys Commun 184:1562-1569

15. Biener J, Hodge AM, Hamza AV (2005) Microscopic failure behavior of nanoporous gold. Appl Phys Lett 87:121908

16. Sun Y, Kucera KP, Burger SA, Balk TJ (2008) Microstructure, stability and thermomechanical behavior of crack-free thin films of nanoporous gold. Scr Mater 58:1018-1021

17. Biener J, Hodge AM, Hamza AV, Hsiung LM, Satcher JH Jr (2005) Nanoporous Au: a high yield strength material. J Appl Phys 97:024301

18. Maaroof AI, Cortie MB, Smith GB (2005) Optical properties of mesoporous gold films. J Opt A: Pure Appl Opt 7:303-309

19. Maaroof AI, Gentle A, Smith GB, Cortie MB (2007) Bulk and surface plasmons in highly nanoporous gold films. J Phys D Appl Phys 40(18):5675-5682

20. Dixon MC, Daniel TA, Hieda M, Smilgies DM, Chan MHW, Allara DL (2007) Preparation, structure, and optical properties of nanoporous gold thin films. Langmuir 23(5):2414-2422

21. Teperik TV, Popov VV, Garcia de Abajo FJ (2004) Total resonant absorption of light by plasmons on the nanoporous surface of a metal. Proceedings of the conference "Nanophotonics 2004", Nizhni Novgorod, Russia May 2-6, 2004

22. Cortie MB (2004) The weird world of nanoscale gold. Gold Bull 37(1-2):12-19

23. Zhang J, Ou J-Y, Papasimakis N, Chen Y, MacDonald KF, Zheludev NI (2011) Continuous metal plasmonic frequency selective surfaces. Opt Express 19(23):23279-23285

24. Cortie MB, Maaroof AI, Smith GB (2005) Electrochemical capacitance of mesoporous gold. Gold Bull 38(1):14-22

25. Cortie MB, Maaroof AI, Mortari A, Wuhrer R (2006) Applications of nano and mesoporous gold in electrodes and electrochemical sensors. IEEE. doi:10.1109/ICONN.2006.340669

26. Xu X, Gibbons TH, Cortie MB (2006) Spectrally-selective gold nanorod coatings for window glass. Gold Bull 39(4):156-165

27. Ruffato G, Romanato F, Garoli D, Cattarin S (2011) Nanoporous gold plasmonic structures for sensing applications. Opt Express 19(14):13164-13170

28. Zhang J, Ou J-Y, MacDonald KF, Zheludev NI (2012) Optical response of plasmonic relief meta-surfaces. J Optic 14:114002-114008

29. Zheng L-T, Wei Y-L, Gong H-Q, Qian L (2013) Application progress of nanoporous gold in analytical chemistry. Chinese JAnal Chem 41(1):137-144

30. Yuan L, Liu HK, Maaroof A, Konstantinov K, Liu J, Cortie M (2007) Mesoporous gold as anode material for lithium-ion cells. J New Mater Electro Syst 10:95-99

31. Jurgens B, Kubel C, Shulz C, Nowitzki T, Zielasek V, Biener J, Biener M, Hamza AV, Baumer M (2007) New gold and silver-gold catalysts in the shape of sponges and sieves. Gold Bull 40(2):142-149

32. Frenkel AI, Vasic R, Dukesz B, Li D, Chen M, Zhang L, Fujita T (2012) Thermal properties of nanoporous gold. Phys Rev B 85(195419):1-7 